\title{
Inclusive Education in Thailand
}

\author{
Kanokporn Vibulpatanavong \\ Department of Curriculum and Instruction \\ Srinakharinwirot University \\ Bangkok, Thailand \\ kanokpornv@g.swu.ac.th
}

\begin{abstract}
This paper discuses Thailand's policies on education for persons with disabilities, particularly inclusive education. It also explores challenges that the country is facing in promoting inclusive education and discusses how Thailand can promote inclusive education for students with disabilities.
\end{abstract}

\section{Keywords-inclusive education, Thailand, special education}

\section{INTRODUCTION}

The international community is moving toward inclusive education. Salamanca Statement and Framework for Action calls for the government to give priority to inclusive education as it is the most effective mean in combating discriminator attitudes and achieving education for all. The fourth Sustainable Development Goal calls for international countries to "ensure inclusive education and quality education for all and promote lifelong learning" by the year 2030[1].In addition, Convention on the Rights of Persons with Disabilities states that countries need to ensure that "persons with disabilities can access an inclusive, quality and freeprimary education and secondary education on an equal basis with others inthe communities in which they live" [2]

In Thailand the number of students with disabilities who are attending regular schools increased significantly during the past few years (Office of the Education Council, 2015). This paper discuses Thailand's policies on education for persons with disabilities, particularly inclusive education. It also explores challenges that the country is facing in promoting inclusive education and discusses how Thailand can promote inclusive education for students with disabilities.

\section{POLICIES ON EDUCATION FOR PERSONS WITH DISABILITIES}

In Thailand, several important documents regarding education for Thai children mention education for children with disabilities. However, most of the documents do not state where education for children with disabilities should take place. In 2002, the Thai government announced Compulsory Education Act (2002). The act states that all Thai children aged between 7-16 years old are required to be enrolled in school except the children who have completed 9 years of education. Section 12 states that Ministry of Education, Education Service Area Offices, Local Administration, and education institutions organize education specially for children with physical, emotional, intellectual, social, communication and learning impairments, or children who cannot depend on themselves, or children without carers, disadvantaged children, children with giftedness, so that the children receive compulsory education through appropriates programs and methods, with accommodations, materials, services, and assistances according to their needs, in order to ensure opportunities and equality to achieve compulsory education.

Persons with Disabilities Empowerment Act, B.E. 2550 [3] states that persons with disabilities are entitled to "education as set forth in the legislation on national education or the national education plan, which suits their physical and mental condition in a specific educational institute, a general education institute, and alternative education or non-formal education, where the agencies involved shall be responsible for providing suitable and necessary facilities, medias, services and any other educational assistance for disabled persons". The act ensures the rights of persons with disabilities to education, however, education for persons with disabilities can take place in a specific educational institute or a general education institute. Although education for persons with disabilities can be formal education or non-formal education.In 2008, the Thai government approved Education for Persons with Disabilities Act B.E. 2551[4]. The act states that "persons with disabilities have the right to education as follows: (1) free education from birth, or when a disability occurs, until the end of life, with education technologies, accommodations, medias, services, and supports. (2) choose educational services, institutions, systems, and types by considering ability, interest, needs of the person with disability. (3) iquality education with quality standard and assurance including curriculum, instruction, assessment, appropriate to the need of each type of disability and each person.The Education for Persons with Disabilities Act does not provide a statement in support of education for persons with disabilities in regular settings over special settings. However, for the first time, the act states that persons with disabilities have the right to "choose" the educational institutions or systems.Giving persons with disabilities the right to choose is a significant progress as it empowers persons with disabilities in making decisions regarding their own education.

In 2017, the Thai government has announced the National Education Plan for the Year 2017 -2036[5]. The plan sets five major goals to be achieved by the year 2036, one of which is that all people in Thailand have access to quality education which meets education standards. An indicator of success for 
the goal is that people aged $6-14$ have access to free primary and lower secondary education and all person with disability are given appropriate educational services. In addition, the plan adopts four educational concepts including: (1) Education for All, (2) Inclusive Education, (3) Sufficiency Economy, (4)All for Education

The national education plan refers to inclusive education "as education for all learners. Disadvantaged students due to socioeconomic reasons. The government must provide resources for this group of students so that they are given equal opportunities to education according to their potential and readiness. Students with special needs which include students with physical, mental, intellectual, social, emotional, communication, and learning impairments, and students who cannot depend on themselves, or students without guardians. The students have the right to education alongside regular students, in case that they are able to do so, in order that they are able to exchange knowledge, ideas, and adjust themselves to other people in the community, or they have the right to education specially organized for them depending on the level of their disabilities."

According to the national education plan, the Thai government clearly adopt inclusive education as its one of the policies. However, the plan is not legally binding. Nonetheless, it provides a set of goals for the country to improve education for persons with disabilities.

The national education plan also may define inclusive education differently from international organization such as UNESCO. The plan states that students with disabilities have the right to education alongside regular students, in case that they are able to do so, meaning that there may be some students with disabilities who cannot learn alongside regular students. UNESCO [6], however, defines inclusion as:

A process of addressing and responding to the diversity of needs of all learners Through increasing participation in learning, cultures and communities, and reducing exclusion within and form education. It involves changes and modifications in content, approaches, structures and strategies, with a common vision which covers all children of the appropriate age range and a conviction that it is the responsibility of the regular system to educate all children.

Although the laws and policies in Thailand reflect that the Thai government is committed to improving education for persons with disabilities, much further progresses are needed to be made. For example, despite the law to provide free education for persons with disabilities at all educational levels, including tertiary level. Only $0.8 \%$ of persons with disabilities in Thailand completed Bachelor Degree. One reason could be that although the Thai government provides tuition fees for persons with disabilities, there are other expenses, such as transportation and living expenses. However, the percentage may also reflect the quality of education for persons with disabilities during primary and secondary education which could be inadequate in preparing them for university education.

According to the Ministry of Education, disabilities in Thailand are categorized into 9 types: (1) visual impairments, (2) hearing impairments, (3) physical and/or health impairments, (4) autism, (5) intellectual disabilities,(6) specific learning disorders, (7) emotional and/or social impairments, (8) language and/or speech impairments, (9) multiple disabilities.

Children who have been identified with one of the 9 types of disabilities are protected by the Education for Persons with Disabilities. However, the categorization can also lead to labelling and stereotypes. It is therefore important to attempt to reduce categorization and provide supports for all students who need the supports without categorization, although it would be a practice that are unfamiliar to a large number of teachers.

\section{STUdENTS WITH DisABILITIES AND REGULAR SCHOOLS IN THAILAND}

In Thailand, compulsory education includes six years of primary education and three years of lower secondary education. Compulsory education in Thailand is free in public education institutions. The Thai government also has a policy to promote access to three years of early childhood education, and three years of upper secondary education for general Thai students. However, as early childhood education and upper secondary education are not compulsory, it can be challenging to ensure access for students with disabilities to education in regular settings.

There are three main types of schools in Thailand. Ministry of Education schools, Local Administration schools, and private schools. In Bangkok, out of the total of

However, the number of students with disabilities in regular schools in Thailand increased substantially from approximately 60,000 in 2012 to approximately 25,000 in 2015 [7]. Out of the 427 Bangkok Metropolitan Schools, 310 are regular schools and 127 are called integration schools. It is a policy of Bangkok Metropolitan Administration that schools accommodate all children in the areas. However, in practice, the 310 regular schools can referred students with disabilities to one of the integration schools nearby if the schools find themselves unequipped to accommodate students with disabilities, particular students with significant disabilities.

Most public regular schools in Thailand that accept children with disabilities are called "integration" schools rather than inclusive schools. Integration schools varies in how the accommodate students with disability. In most integration schools, students with disabilities attend one of the following:

(1) Full time special classrooms

(2) Regular classrooms for part of the day and special classrooms for part of the day

(3) Full time regular classrooms

Special education teachers have responsibility in preparing students with disabilities for regular classrooms and to work with regular teachers in transferring students with 
disabilities to regular classrooms. However, some students with disabilities in regular schools in Thailand attend special classrooms full-time all through schools and participate only in extra-curricular activities with regular students.

[8], sometimes students with disabilities in regular classrooms in Thailand may "represent only physical inclusion and may not represent an appropriate education for those students". In addition, "adaptations and modifications for students with special needs in general classrooms are uncommon in Thailand" [9]. Trainings of regular teachers on curriculum and instructional adaptations could enhance the inclusion of all students in regular classrooms.

While it seems that Thailand has made substantial progress in providing access to education in regular schools for students with disabilities, it is now the time that the country moves forward to focus on quality of education that children with disabilities are receiving in regular schools.

\section{BARRIERS TO INCLUSIVE EDUCATION IN THAILAND}

While Thailand is trying to promote inclusive education, there are barriers that the country needs to overcome, including policy barriers, physical barriers, attitudinal barriers, and knowledge barriers.

Policy barriers. As mentioned, although Thailand has set a goal to promote education for persons with disabilities, the concept of inclusive education needs to be further refined. Schools in Thailand should embrace as a policy to educate all children in the community regardless of the students' abilities or readiness. The policy should reflect the idea that schools will ensure that children with disabilities are able to access learning opportunities in schools and are accepted as members of school communities, instead of the idea that students with disabilities need to meet certain level of ability to be able to enroll in regular schools.

Physical Barriers. According to[10], "in Thailand, universal design is not well placed, and this drawback discourageschildrenwithdisabilities from participating in mainstream schools". The physical barriers do not only include the infrastructures and the environmental arrangements in schools, but also transportation from home to school. While travelling by public transportation in a busy city, such as Bangkok, can be challenging for general people in Bangkok, it can be even more challenging for persons with physical disabilities.

Attitudinal Barriers. There are cultural influences of attitudes towards disability in Thailand. For example, Laskar, Vibulpatanavong, and Evans (2017) found that 91.7\% of theThai students responded "yes" to feeling "songsarn" for students with disabilities. Songsarn can mean pity, or feeling sorry for someone, or compassion. [11]Found that Thai students are often taught to feel "songsarn" for people who are in difficult situation, particularly peers with disabilities. There are benefits in so doing because Thai students are expected to feel "songsarn" for and then try to help peers with disabilities. However, this could lead to the feeling that peers with disabilities are of lower status. Therefore, it is important that Thai students are not only taught to help their peers with disabilities, but to understand and respect their peers with disabilities.

Knowledge Barriers. Agbenyegaand Klibthong(2015), some teachers did not know how to modify curriculum for students with disabilities and they "often used the same approaches and curriculum to teach the whole class irrespective of the individual children's unique needs".

In addition, [12] found that many upper primary school students in Thailand did not know what specific learning disorder is. When given a description of a hypothetical student with specific learning disorder, many students indicated that the hypothetical student did not work hard enough and the solution for the hypothetical students is to work harder. The misunderstanding could interfere with the friendship between regular students and students with specific learning disorder.

Improving pre-service regular teacher training to includes curriculum and instructional adaptation for students with disabilities in regular students is highly important. It is because the responsibility in meeting the needs of students with disabilities are no longer solely the responsibility of special education teachers, but also the responsibility of regular teachers and all school staff.

\section{Promoting INCLUSIVE EdUCATION IN THAILAND}

In order to promote inclusive education in Thailand, it is important for the government to review the present practice of inclusive education in Thailand in order to understand its strength and limitation so that the country can move forward in the right direction. Limited research has been conducted on the achievement of students with disabilities in regular schools in Thailand, although it is important ensure that students with disabilities in regular students learn knowledge and skills needed for them to be an active member of the community.

\section{References}

(Thai language version). Journal of Research and

[1] United Nations (2015). Transforming our world: the 2030

[2] United Nations (2006). Convention on the Rights of PersonswithDisabilities. Retrieved from: www.un.org/disabilities/.../convention/convention

[3] Thai Government (2007). Persons with Disabilities

[4] Thai government (2008). Education for Persons with Disabilities Act, B.E. 2551 (Thai language version). Retrieved from:dep.go.th/?q=th/node/432

[5] Thai Ministry of Education (2017). National Education Plan(Thai language version). Retrieved 
from:backoffice.onec.go.th/uploaded/Outstand/2017EdPlan60-79.pdf

[6] UNESCO (2009). Guidelinesfor inclusion: ensuring access to education for all.Retrieved from:unesdoc.unesco.org/images/0014/001402/14022 4e.pdf

[7] Office of the Educational Council (2013). National Education Statistics for the Year 2011-2012 (Thai language version). Retrieved from: https://www.msociety.go.th/article_attach/19341/20693.pdf

[7] Office of the Educational Council (2016).National EducationStatistics for the Year 2014-2015 (Thai language version). Retrieved from: www.moe.go.th/moe/upload/news20/ FileUpload/397 19-2357.pdf

[8] [9] Kosuwan, K., ViriyangkuraY. Swerdlik, M. E., (2014), Special Education Today in Thailand, In A. F. Rotatori, J. P. Bakken, S. Burkhardt , F. E. Obiakor, U. Sharma (ed.) Special Education International Perspectives: Practices Across the Globe (Advances in Special Education, Volume 28) (pp.689- 721). Emerald Group Publishing Limited. 31 July -2 August 2017, Borneo Conference Center, accessible_pdf.pdf

[10] Bualar, T. (2016). What has gone wrong with inclusiveeducation in Thailand?.Journal of Public Affairs.16(2).156-161.

[11] Vibulpatanavong, K. (2017). Influence of culture on social

[12] Vibulpatanavong (2017). Attitudes of Upper Primary School 